\title{
The State of Cancer Care in America: Impact of State Policy on Access to High-Quality Cancer Care
}

Terrell Johnson, MPA ${ }^{1}$; Lindsey A.M. Bandini, $\mathrm{MPH}^{1}$; Kara Martin, MPH${ }^{1}$; Lee Jones, MBA ${ }^{2}$; Jennifer Carlson ${ }^{3}$; Ronald S. Walters, MD, MBA, MHA, MS; and Robert W. Carlson, MD ${ }^{1}$

\begin{abstract}
Health policy in America has shifted rapidly over the last decade, and states are increasingly exercising greater authority over health policy decision-making. This localization and regionalization of healthcare policy poses significant challenges for patients with cancer, providers, advocates, and policymakers. To identify the challenges and opportunities that lay ahead of stakeholders, NCCN hosted the 2019 Policy Summit: The State of Cancer Care in America on June 27, 2019, in Washington, DC. The summit featured multidisciplinary panel discussions to explore the implications for access to quality cancer care within a shifting health policy landscape from a patient, provider, and lawmaker perspective. This article encapsulates the discussion from this NCCN Policy Summit.
\end{abstract}

J Natl Compr Canc Netw 2020;18(4):400-404 doi: $10.6004 /$ jnccn.2020.7541
The American health system has experienced substantial changes over the last decade. A new phenomenon is the growing authority of states over health policies historically administered by federal policymakers. This shift, partially introduced by the Affordable Care Act's (ACA) State Innovation Waiver provision, has been expanded considerably by the Trump administration, increasing state experimentation in network adequacy, essential health benefits, and other facets of care to unprecedented levels. Although supporters of this policy shift remark that states are, and always have been, fertile grounds for healthcare innovation, oncology stakeholders express concern for the erosion of comprehensive care across a new patchwork of state innovation projects and patient protection laws. ${ }^{1}$ To consider the implications of this development, NCCN hosted the 2019 Policy Summit: The State of Cancer Care in America: The Impact of State Policy on Access to High-Quality Cancer Care. The summit convened 2 multistakeholder panels and included a morning keynote to examine the challenges and opportunities for high-quality cancer care posed by new state authority over health policy. This article provides a technical review of the policy perspectives highlighted during summit discussions and keynote lectures.

\section{Shifting Regulatory Authority From the Federal} Government to States and the Implications for Patient Access to High-Quality Cancer Care The ACA was signed into law March 23, 2010. ${ }^{2}$ Although divisive, the bill stands as a landmark development in health policy. Nine years later, increasing health costs, stagnant advances in healthcare outcomes, and an aging population signal the need for innovation. In the absence of bipartisan Congressional action, The Centers for Medicare \& Medicaid Services (CMS) are providing increased abilities for states to reform commercial and state-funded health plans through waiver authorities. NCCN assembled a multidisciplinary panel of policy strategists, researchers, patients, and oncology practitioners to discuss at length the development of this shift, the 
federal regulatory instruments in use, and the potential consequences for patients with cancer and survivors.

Providing states with operational flexibility under Medicaid, the Section 1115 waiver has been in the Social Security Act since the 1960s. ${ }^{1}$ Responding to pushback of restrictive demonstration goals by the healthcare system, CMS has taken a series of steps to widen the parameters of the waiver, including reducing patient protection standards. In November 2017, CMS broadened application criteria for 1115 waivers, removing "increasing health coverage" as an objective of projects. Waiver guidance in January 2018 would expand states' ability to restrict patient eligibility by permitting the use of work and community engagement requirements.,

Section 1332 waivers have similarly experienced a broadening of authority from CMS. Originating from the ACA, 1332 waivers authorize innovation projects to provide beneficiaries with health coverage as long as they guarantee equal protections provided under the exchange plans. ${ }^{1}$ Since 2016, most states have used the waiver to reimburse insurers covering high-risk beneficiaries (also known as reinsurance programs). In October 2018, CMS issued guidance no longer requiring proposals to demonstrate comparable coverage for residents. Furthermore, states no longer need to prove waivers include coverage that qualifies as "minimum essential coverage," which has significant implications for patient access to cancer care. CMS supplemented the waiver guidance with a white paper outlining new methods for using the 1332 waiver. $^{5-7}$

Proponents for the continued expansion of these regulatory tools cite early findings as evidence that states know what is best for states. In the case of 1332 waivers, outcomes have shown that reinsurance programs have succeeded in stabilizing individual markets and lowering premiums. Of the 7 states approved for reinsurance programs prior to 2019 (Alaska, Maine, Maryland, Minnesota, New Jersey, Oregon, and Wisconsin), premium savings range from $6 \%$ to $43 \%$, with an average savings per state of 19.9\%. ${ }^{8}$ In Texas, the Healthcare Transformation and Quality Improvement Program, approved under an 1115 waiver, has reduced care costs by $\$ 3.8$ billion over a 5-year period. Likewise, Michigan's 1115 waiver program (Healthy Michigan Plan) reduced the average cost of uncompensated hospital care by $\$ 3.4$ million and increased Medicaid coverage among nonelderly adults by $5 \% .{ }^{1,9,10,11}$

Conversely, some reports have raised significant concerns for the continual expansion of waivers. In March 2018, Arkansas used the 1115 waiver to attach work requirements to Arkansas Works, the state Medicaid program. By December, the uninsured rate among 30- to 49-year-old Arkansans eligible for Medicaid increased 4\% even as the employment rate declined from $42.4 \%$ to $38.9 \% .^{1,12}$ In Indiana, a cost-benefit study projected the implementation of work/community engagement requirements would remove $>50,000$ nonelderly Medicaid eligible adults from the rolls. ${ }^{13}$ For oncology, these findings raise legitimate concerns, because limited access to comprehensive healthcare threatens early detection and optimal treatment outcomes. Additionally, policy concepts, such as work requirements, pose significant barriers to a patient population that is unable to work, or work consistently, during treatment. ${ }^{1}$ Stakeholders have also highlighted reporting standards of these innovation projects as a cause for concern. A recent Government Accountability Office (GAO) study revealed that several approved waivers contained scant evaluation processes that significantly challenged the data's usefulness in informing future regulatory policy. ${ }^{14}$

In the background of this debate, CMS continues to expand states' capacity to alter healthcare. The administration recently finalized a rule expanding access to short-term limited duration (STLD) plans, which are a form of insurance exempt from ACA compliance and can deny coverage to patients with cancer under the guise of a preexisting condition, impose annual or lifetime limits on needed therapies, and deny coverage of cancer screenings and preventive care. ${ }^{15}$ Additionally, states such as Tennessee and Alaska are working with the administration to explore the possibility of block grant funding; a form of fixed federal funding that many oncology stakeholders believe would harm the quality of care or force patients to take on high cost-sharing. ${ }^{16}$ As deliberation over the role of states in healthcare continues, many oncology stakeholders share concerns that innovation will give way to a corrosion of federal patient protections and a reduction in the quality of cancer care American patients receive. ${ }^{1}$

Trends in Cancer Care Policy at the State Level As the United States grapples with altering a complex healthcare system, many states are setting policy trends based on regional demographics, local resources, and recognized political identity. NCCN assembled a diverse group of panelists, representing 6 states and various perspectives, to address the state and regional trends observed in health policy. Although opinions and perspectives varied, panelists all agreed that state-level health policy extends well beyond state boundaries, and carries considerable health, clinical, and economic implications for neighboring patients, providers, and hospitals. ${ }^{17}$

Resource allocation in healthcare is inextricably linked to states' economic health, political environment, and projected growth, creating variations across different states and regions. In many states, Medicaid accounts for $30 \%$ of total state spending. ${ }^{18}$ As overall health costs increase, states are increasingly adjudicating who and what to cover through state-run Medicaid programs. 
Under the ACA, states can receive federal dollars to expand their Medicaid program, covering constituents with a household income below $138 \%$ of the federal poverty level. States that have expanded coverage show improved access to timely care, particularly for racial minorities, whereas those that have not are exhibiting higher uninsured rates. ${ }^{19}$ In Texas, a state that has not approved expansion, 4.8 million residents aged $<65$ years lack health insurance. ${ }^{17,20}$

Although Medicaid expansion has increased rates of coverage in some states, detractors highlight the unsustainability of the program and its inability to address increasing healthcare costs. In the Northeastern region of the United States, Massachusetts is working to answer this critique through their Medicaid program, MassHealth. Last year, in an effort to manage program costs, the state restructured MassHealth, moving 1.2 million enrollees into accountable care organizations or managed care organizations reimbursed through capitated payments. Massachusetts has also created a Health Policy Commission and Price Variation Commission to ensure healthcare spend in the state does not exceed gross state product. Taking notice, other states such as New York, Maryland, and Connecticut are taking steps to establish similar commissions or tasking existing regulatory bodies with considering cost. ${ }^{17,21}$

As some regions implement new cost-containment policies, others are reevaluating longstanding tools for opportunities to improve quality. Step therapy (ST) is a utilization management tool requiring the use of a preferred treatment by the insurance provider before a prescribed therapy is covered..$^{19}$ Introduced in an effort to reduce overuse of expensive tests and treatments, ST has been criticized by oncology stakeholders for not containing quality-protecting guardrails or procedures that are critical to severe diseases such as cancer. Providers and patient advocates fault the tool for harming patient outcomes due to clinically inadequate treatment, slow approval times, and excessive administrative burden. Dr. Shiven Patel, panel member and investigator at the Huntsman Cancer Institute at the University of Utah, noted that such prior authorization can lead to dire outcomes for patients, specifically in cases of delayed treatment for oral chemotherapies. "Unfortunately," stated Dr. Patel, "I and my colleagues have had patients die waiting for those drugs to be approved."17,22

States are increasingly passing bills to regulate ST and prior authorization in response to undesirable patient experiences and outcomes. ${ }^{23}$ In 2017, Texas lawmakers and patient advocate groups passed Senate Bill (SB) 680, legislation mandating that plan sponsors consider clinical review criteria (such as clinical practice guidelines) when implementing ST. ${ }^{22,24,25}$ Other states have followed suit, introducing or passing similar legislation that provides guardrails to ST. In 2019, both Ohio and Massachusetts introduced legislation requiring ST protocols to be based on medical evidence and clinical practice guidelines. ${ }^{26,27}$ Ohio's bill was signed into law in January 2020, whereas Massachusetts stakeholders are still discussing House Bill (HB) $1853 .{ }^{17}$

Encouragement of drug pricing transparency is another method states are using to combat increasing costs. Drug pricing transparency elements were reported in upwards of 30 state law drafts in 2019. ${ }^{28}$ Many oncology stakeholders agree that transparency laws can be effective; however, skepticism remains regarding the impact of recently introduced policy solutions. Most agree that additional research is needed to identify the best way to relay cost information to patients, pharmacy benefit managers, and payers. ${ }^{17}$

As healthcare spend data become more readily available, states are considering a variety of ways to leverage these data. States are increasingly tasking regulatory departments with reviewing prescription drug costs. In some cases, states are creating independent commissions to assess costs and the ability for state Medicaid programs to cover high-cost drugs. As a resource, many of these commissions are using the Institution for Clinical and Economic Review's (ICER) Value Assessment Framework (VAF) to measure the worth of treatment options. ${ }^{17}$ Although these frameworks provide insight, stakeholders note that the assessments' prioritization of cost leaves several variables outside of the equation used by pharmacy and therapeutics committees. Patients and patient advocates have also called attention to a lack of patient input and infrequency of review as weaknesses of the ICER VAF. ${ }^{29-31}$ Panelists echoed similar sentiments, and many agreed that further debate is needed to determine what number or calculation delivers the appropriate price threshold for therapies. ${ }^{17}$

The cost of healthcare is not unique to states, and stakeholders caution against losing patient centrality in the effort to reduce healthcare cost. ${ }^{17}$ Most patients with cancer, even those with health insurance, report some type of financial hardship. ${ }^{32}$ Even when financial assistance programs are available, the onus of navigating the complex and ever-changing healthcare system is often on patients. ${ }^{17}$ Efforts to control costs, including Medicaid expansion, ST legislation, and hard healthcare spend targets, all have the potential to limit access. A geographic move is one of the limited options available to patients to combat poor state policies, which poses a whole new set of challenges for individuals with cancer. ${ }^{17}$

\section{Evolving Role of States in Ensuring Access to High-Quality Cancer Care}

Adjusting to a larger role in health policy, state lawmakers are seeking effective strategies to address emerging 
healthcare issues. On June 6, 2019, the National Governors Association, National Conference of State Legislatures, and National Academy for State Health Policy convened a multistate leadership meeting to highlight best practices in resolving various health system challenges. ${ }^{33}$ Although anecdotal stories of success exist, many state policymakers are operating with fixed budgets, small teams, and imperfect data. Senator Matt Lesser, Deputy Majority Leader of the Connecticut State Senate, provided the morning keynote, highlighting recent developments in Connecticut and detailing his experience legislating in this landscape.

Expansion of state authority has produced many opportunities for Connecticut to improve patient access to timely, affordable, and high-quality healthcare. In 2018, the State Senate introduced SB 398, permitting the Connecticut Insurance Department to levy fines on insurance providers in noncompliance with the state's ST restrictions. ${ }^{34,35}$ The same year, Insurance Commissioner Katharine Wade issued regulatory guidance requiring STLD plans to cover essential health benefits. ${ }^{36}$ In a concerted effort to protect patients with cancer, the state also passed anticancer parity legislation protecting equal patient cost-sharing implications for both oral and intravenous chemotherapy drugs. ${ }^{34}$

Although opportunities to innovate persist in Connecticut, considerable challenges remain for policymakers. A ubiquitous concern is that Connecticut, like many states, works with a fixed budget. Subsequently, the fate of many state initiatives is bound to their cost-benefit analysis forecast. The limited availability of human capitol also limits legislators' ability to work effectively. In 2019, Connecticut legislators discussed addressing surprise billing, spread pricing, drug parity, drug importation, and revising ST statutes. Senator Lesser noted that to stay informed on this portfolio of policy issues, he had at his disposal only 1 full-time staffer, 1 part-time lawyer, and interns. ${ }^{34}$

Despite these barriers, progress was achieved when policymakers tapped into the correct resources. An effective resource in Connecticut is the power of the patient voice. Senator Lesser credits his own cancer journey with helping him identify the value in patient experience. "I was able to learn from my own experience what worked well, what didn't, and what blessings I had as a state legislator that many of my neighbors, my constituents, the people that I work for, simply do not have and aren't able to access." ${ }^{34}$

This insight helped advance important legislation in 2018. Connecticut law did not mandate insurance coverage for infertility treatment of patients with cancer. For female patients in Connecticut, the omission of cancer coverage corresponded to $\geq \$ 15,000$ in out-of-pocket costs for mature oocyte cryopreservation. ${ }^{34}$ To resolve this oversight, Senator Lesser introduced Proposed Bill 5644 (PB 5644) in 2013, amending existing law to require fertility preservation in patients with cancer or anyone with a medical condition that threatened fertility. The bill languished in committee for 4 years until a 34-yearold cancer survivor shared her story of struggling for access to the service. "It was the first, last, and only time I've ever seen a committee of the legislature give a member of the public an ovation after they've given testimony," said Senator Lesser. The State House and Senate unanimously approved SB 7124, a reintroduced version of the legislation, in 2017. ${ }^{34}$

Senator Lesser has led several efforts to improve healthcare in Connecticut since then, including sponsoring legislation requiring health carriers to submit annual reports concerning parity and introducing a bill requiring investigation of the public health impact of prescription nonadherence. The lessons elicited from those initiatives are significant, but he highlighted his experience passing SB 7124 as a watershed moment. "This wasn't something I did. It is not something I could have done," stated Senator Lesser. "But it does show the incredible power of individual advocates at the state level." His colleagues have not wasted the lesson. Earlier this year, the story of a resident and breast cancer survivor helped amplify HB 7124, legislation requiring insurance providers to cover baseline mammograms for any woman aged $\geq 30$ years, which passed unanimously. ${ }^{34}$

\section{Conclusions}

Barring an ideological pivot by the current federal administration, the continued expansion of states' authority over critical matters of health policy seems inevitable. In this evolving role, states may help identify innovative solutions to some of America's most pressing healthcare issues. However, the many and varied forms and styles of healthcare projects, combined with overextended and underfunded state governing bodies, may create a patchwork of state policies that threatens access to high-quality cancer care. As state lawmakers advance, amend, or oppose legislation, they are best served by elevating the voice and experiences of patients in their legislative chambers. "It shouldn't be a roll of the dice," noted Lee Jones, patient advocate and summit panel speaker. "Quality cancer care should not depend on which state a patient lives in."

Submitted December 12, 2019; accepted for publication January 292020.

Disclosures: The authors have disclosed that they have not received any financial consideration from any person or organization to support the preparation, analysis, results, or discussion of this article.

Correspondence: Terrell Johnson, MPA, National Comprehensive Cancer Network, 3025 Chemical Road, Suite 100, Plymouth Meeting, PA 19462. Email: tjohnson@nccn.org 


\section{References}

1. Shifting regulatory authority from the federal government to states and the implications for patient access to high quality cancer care. Panel discussion at the NCCN Policy Summit: The State of Cancer Care in America: The Impact of State Policy on Access to High-Quality Cancer Care; June 27, 2019; Washington DC.

2. HHS.gov. What is the Affordable Care Act? Accessed September 25 2019. Available at: https://www.hhs.gov/answers/affordable-care-act/ what-is-the-affordable-care-act/index.html

3. Medicaid.gov. Section 1115 demonstrations. Accessed September 25, 2019. Available at: https://www.medicaid.gov/medicaid/section-1115demonstrations/index.html

4. Neale B. Opportunities to promote work and community engagement among Medicaid beneficiaries. Accessed September 20, 2019. Available at: https://www.medicaid.gov/sites/default/files/federal-policyguidance/downloads/smd18002.pdf

5. Kaiser Family Foundation. Tracking Section 1332 state innovation waivers Accessed September 20, 2019. Available at: https://www.kff.org/healthreform/fact-sheet/tracking-section-1332-state-innovation-waivers/

6. Department of Health and Human Services (HHS). State relief and empowerment waivers. Accessed September 24, 2019. Available at: https:// www.federalregister.gov/documents/2018/10/24/2018-23182/staterelief-and-empowerment-waivers

7. Centers for Medicare \& Medicaid Services. Section 1332 state relief and empowerment waiver concepts: discussion paper. Accessed September 20, 2019. Available at: https://www.cms.gov/CCIIO/Programs-andInitiatives/State-Innovation-Waivers/Downloads/Waiver-ConceptsGuidance.pdf

8. Sloan C, Rosacker N, Carpenter E. State-run reinsurance programs reduce ACA premiums by $19.9 \%$ on average. Accessed September 24, 2019. Available at: https://avalere.com/press-releases/state-run-reinsuranceprograms-reduce-aca-premiums-by-19-9-on-average

9. Texas Health and Human Services. Report: independent evaluation of Texas' Uncompensated Care (UC) program and Delivery System Reform Incentive Payment (DSRIP) program. Accessed September 25, 2019. Available at: https://hhs.texas.gov/sites/default/files/documents/lawsregulations/reports-presentations/2016/eval-uncompensated-caremedicaid-payments-tx-hospitals-role-tx-uc-pool-aug-2016.pdf

10. Levy $\mathrm{H}$, Buchmueller T. Health Michigan plan evaluation domain II - reduction in the number of uninsured. University of Michigan Institute for Healthcare Policy \& Innovation. Accessed September 23, 2019. Available at: https://www.michigan.gov/documents/mdhhs/ Domain_II_-_Reduction_in_Number_of_Uninsured_647135_7.pdf

11. Buchmueller T, Levy H, Nikpay S, Rhodes J. Healthy Michigan plan evaluation domain I - hospital uncompensated care. University of Michigan Institute for Healthcare Policy \& Innovation. Accessed September 23, 2019. Available at: https://www.michigan.gov/documents/mdhhs/ Domain_I_-_Reduction_in_Uncompensated_Care_647133_7.pdf

12. Sommers BD, Goldman AL, Blendon RJ, et al. Medicaid work requirements - results from the first year in Arkansas. N Engl J Med 2019;381:1073-1082.

13. Musumeci MB, Foutz J, Garfield R. How might older nonelderly Medicaid adults with disabilities be affected by work requirements in section 1115 waivers? Accessed September 23, 2019. Available at: https://www.kff. org/medicaid/issue-brief/how-might-older-nonelderly-medicaid-adultswith-disabilities-be-affected-by-work-requirements-in-section-1115waivers/

14. United States Government Accountability Office. Medicaid demonstrations: evaluations yielded limited results, underscoring need for changes to federal policies and procedures. Accessed September 23, 2019. Available at: http://www.gao.gov

15. Keith K. The short-term, limited-duration coverage final rule: the background, the content, and what could come next. Accessed September 24 2019. Available at: https://www.healthaffairs.org/do/10.1377/ hblog20180801.169759/full/

16. Rudowitz R. 5 Key questions: Medicaid block grants \& per capita caps. Accessed September 23, 2019. Available at: https://www.kff.org/ medicaid/issue-brief/5-key-questions-medicaid-block-grants-percapita-caps/
17. Trends in cancer care policy at the state level. Panel discussion at the NCCN Policy Summit: The State of Cancer Care in America: The Impact of State Policy on Access to High Quality Cancer Care; June 27, 2019; Washington, DC.

18. Schneider A, Searing A, Alker J, et al. Medicaid and state budgets: checking the facts (yet again). Accessed September 26, 2019. Available at: https://ccf.georgetown.edu/2019/02/28/medicaid-and-state-budgetschecking-the-facts-yet-again/

19. Adamson BJ, Cohen AB, Estevez $M$, et al. Affordable Care Act (ACA) Medicaid expansion impact on racial disparities in time to cancer treatment [abstract]. J Clin Oncol 2019;37(Suppl):Abstract LBA1.

20. Texas Alliance for Health Care. The impact of uninsurance on Texas' economy. Accessed September 10, 2019. Available at: http://wrgh.org/ docs/The_Impact_of_Uninsurance_on_Texas_Economy_20190108.pdf

21. Massachusetts Health Policy Commission. 2018 Report on health care cost trends. Accessed September 10, 2019. Available at: https://www. mass.gov/doc/2018-report-on-health-care-cost-trends

22. Fischer MA, Avorn J. Step therapy-clinical algorithms, legislation, and optimal prescribing. JAMA 2017;317:801-802.

23. Fink JL. Laws in 20 states address insurance-mandated step therapy. Accessed September 10, 2019. Available at: https://www.pharmacytimes. com/publications/issue/2019/july2019/laws-in-20-states-addressinsurancemandated-step-therapy

24. National Psoriasis Foundation. Step therapy legislation by state. Accessed September 13, 2019. Available at: http://www.steptherapy.com/steptherapy-legislation-by-state/

25. LegiScan. TX SB680. Relating to step therapy protocols required by a health plan in connection with prescription drug coverage. Accessed September 10, 2019. Available at: https://legiscan.com/TX/text/SB680/ id/1617322

26. The Ohio State Legislature. Permit health insurers to cover pharmacistprovided benefits. Accessed September 10, 2019. Available at: https://www. legislature.ohio.gov/legislation/legislation-summary?id=GA132-SB-265

27. The Commonwealth of Massachusetts. Accessed September 10, 2019. Available at: https://malegislature.gov/Bills/191/H1853

28. Findlay S. States pass record number of laws to reel in drug prices Accessed September 12, 2019. Available at: https://khn.org/news/ states-pass-record-number-of-laws-to-reel-in-drug-prices/

29. Partnership to Improve Patient Care. Analysis finds ICER incorporates only $16 \%$ of feedback received from patient advocates into final value assessments. Accessed September 25, 2019. Available at: https://www. pipcpatients.org

30. Winegarden W. The ICER myth. Available at: https://static1.squarespace. com/static/5886319ba5790a66cf05d235/t/5ae0a7be575d1f3b350e155e/ 1524672450834/IfPA_The+ICER+Myth_April+2018+\%281\%29.pdf. Accessed March 2, 2020.

31. White N, Pace M. Is ICER our Robin Hood? The role of an independent HTA in the Sherwood Forest of US drug pricing. Accessed September 24, 2019. Available at: https://www.iconplc.com/

32. Zafar SY, Peppercorn JM, Schrag D, et al. The financial toxicity of cancer treatment: a pilot study assessing out-of-pocket expenses and the insured cancer patient's experience. Oncologist 2013;18:381-390.

33. National Governors Association. NGA brings together more than 100 health policy leaders to improve capacity for health care services. Accessed September 14, 2019. Available at: https://www.nga.org/news/ press-releases/nga-brings-together-more-than-100-health-policy-leadersto-improve-capacity-for-health-care-services/

34. Lesser M. The evolving role of states in ensuring access to high quality cancer care. Keynote at the NCCN Policy Summit: The State of Cancer Care in America: The Impact of State Policy on Access to High Quality Cancer Care; June 27, 2019; Washington, DC.

35. SB 398. An act concerning penalties for failure to comply with provisions governing the use of step therapy for prescription drugs. Open States. Accessed September 10, 2019. Available at: https://openstates.org/ct/ bills/2018/SB398/

36. Wade K. Short-term, limited-duration health insurance policies. Bulletin HC-121. Accessed September 11, 2019. Available at: https://portal.ct. gov/-/media/CID/BulletinHC121pdf.pdf?la=en 